\title{
Research on the Problems and Countermeasures in the Development of Logistics Clusters in Ningbo
}

\author{
MA Lili \\ Ningbo City Vocational and Technical College \\ Ningbo, China, 315175
}

\begin{abstract}
Under the background of global economic downside risks and Ningbo's "six struggles for three years to climb" action plan, logistics clusters show their unique competitive advantages and significant social and economic benefits. Through investigating the current situation of Ningbo logistics clusters, this paper explores the recent achievements and prominent problems of Ningbo in the development of logistics clusters and makes suggestions for the status quo and problems of industrial clusters in Ningbo.
\end{abstract}

Keywords—Logistics clusters; Development issues; Ningbo

\section{INTRODUCTION}

With the continuous advancement of the "One Belt, One Road" strategy, Ningbo's strategy of creating "one circle and three centers" is in full swing, and the characteristics of the integration of the port city are further highlighted. The idea of the development of Ningbo's innovative logistics industry clusters has continuously introduced new action plans and plans to promote the high-quality construction of the logistics industry.

\section{A. Port cargo throughput ranks first in the world}

Ningbo Zhoushan Port broke through 1 billion tons of cargo throughput in 2017, ranking first in the world for 9 consecutive years. Ningbo Port completed annual cargo throughput of 720 million tons, an increase of $8.4 \%$ year-onyear; completed container throughput of 25.97 million TEUs, an increase of $13.8 \%$ year-on-year, and the growth rate was at the leading level among China's coastal ports. At the same time it also ensures that the container throughput of Ningbo Zhoushan Port continues to rank fourth in the global port, and its growth rate continues to rank first among the top five container ports in the world.

\section{B. Significant achievements in the transformation and upgrading of Ningbo logistics industry}

After the substantial integration of Ningbo Zhoushan Port was completed, the province's port integration process progressed steadily.[1] The port development pattern of Ningbo Zhoushan Port as the main body, the southeast coastal port of Zhejiang and the Hangzhou Bay Port of Zhejiang North Ring, and the joint development of Yiwu dry port and the inland port are formed. According to the statistics of the province's modern service industry gathering demonstration area in 2017, the operating income of Ningbo Meishan Bonded
Port Logistics Park has reached 208.14 billion yuan, which has become the leader in the development of four " 100 billionlevel" demonstration zones, and paid taxes of 273.99 million yuan to serve the whole province. The industry has continued to play a key role in supporting the development and leading the way.

1) Create a "smart logistics" supervision mode and open the "blocking point" in logistics transshipment.

Since 2017, Ningbo Customs has started to upgrade its technical equipment and develop a mobile application and inspection operation mode based on "Internet Plus". Among them, the safe and intelligent lock mode allows only three customs officers to carry out real-time monitoring of the subordinate landlocks to the port unlocking for thousands of ships and thousands of vehicles in the logistics monitoring center, [2] and promote the smooth flow of logistics and transportation.

2) Create a cold chain logistics distribution center in the Yangtze River Delta to meet market demand.

Ningbo has been listed by the Ministry of Commerce as a key city for the development of cold chain industry. It is the largest import chain of cold chain in Zhejiang Province. The imported cold chain logistics industry in the Yangtze River Delta is relatively concentrated and the facilities are relatively advanced. At present, Ningbo Meishan Bonded Port Area is constructing the first phase of the China Merchants Association cross-border agricultural product cold chain logistics distribution platform and the China Business Alliance "Belt and Road" modern service industry industrial park. [3] Previously, Ningbo Port Cold Chain Logistics Center has become Ningbo's first inspection and quarantine cold chain logistics designated inspection point and the first cold chain customs supervision site, achieving a continuous chain, effectively reducing the importer's demurrage cost and shortening The customs clearance time, in order to achieve the goal of "zero waiting at the port", greatly satisfying the market for high quality imported cold chain food. 


\section{Problems in the development of logistics clusters in Ningbo}

1) Logistics clusters development environment needs further optimization.

The integration of various elements in the logistics clusters is insufficient, and traditional services are still the mainstay. At present, capital, talents, technology and other factors have not yet become new advantages within the clusters, and there is no breakthrough innovation in the regional economy, and the driving force for the Hong Kong city economy is insufficient. In addition, the internal functions of Ningbo Logistics clusters are still mostly based on traditional services, and rarely involve the middle and upper reaches of the supply chain. This kind of clusters-based integrated strength mainly depends on the government, and the core competitiveness is lacking, and to a certain extent. It brings invisible pressure on regional resources.

2) The scale of logistics companies needs to be expand and the competitiveness needs to be improved.

Logistics companies are small in scale and lack core competitiveness. Most of the internal enterprises of Ningbo logistics clusters have similar business directions, [4] resulting in small scale, weak influence on business direction and operation, lack of core competitiveness, and unable to provide professional and strong logistics services to large enterprises or multinational companies. In addition, when forming a logistics clusters, it is too singular and incomplete, which makes the business between the enterprise and the enterprise cross-over, which is not conducive to the coordinated development of the logistics clusters. In addition, some small logistics companies have relatively weak infrastructure. The use of information technology and the role of industrial clusterss are small and weak.

3) The basic elements of the logistics clusters need to be consolidated

Facilities and equipment are behind. Due to the long development time of most logistics enterprises in Ningbo, many information equipments and loading and unloading equipments have not met the current market demand. [5] The service capacity of Ningbo logistics clusters enterprises will gradually lag behind with market competition and market development due to backward equipment facilities. At present, most of the traditional logistics enterprises in Ningbo have transformed into the modern logistics industry, changing the original single function state to the integrated logistics function

The mode of transportation is not standardized. In terms of transportation mode selection, shipping is still the mainstream choice of most logistics companies. In recent years, multimodal transport has been welcomed by most companies because of its advantages [6]. The 18 international routes only account for $10 \%$ of the international ocean transportation trunk line, which limits the development of diversified services.

\section{SUGGESTIONS FOR THE DEVELOPMENT OF LOGISTICS CLUSTERS IN NINGBO}

\section{A. Improve the environment and mechanism of the logistics industry development}

Improve the logistics management mechanism. First, strengthen the coordination of logistics, give full play to the overall management intelligence of the modern logistics leading group and its offices, and strengthen professional staffing. The second is to improve the management of the logistics industry, establish the responsibility of the city's logistics development office, improve the logistics clusters management mechanism, and improve the incentive and restraint mechanism.

Improve and implement the logistics industry policy. The first is to implement the "three mutualities" major customs clearance policy. Accelerate the cooperation between sea and land, open up the logistics network to "block", realize the information sharing of relevant departments, accelerate the docking of logistics clusters and industries. The second is to play the role of the government and implement the "Pan 3315 Plan" as soon as possible. Cultivate high-level talents and highend teams in the fields of e-commerce, port and shipping logistics.

\section{B. Consolidating the basics of logistics clusters}

Introduce or independently develop related facilities and equipment. The logistics equipment is not as good as possible, but it should consider its cost. The low cost and high quality are the priority of the clusters enterprises. The logistics equipment is the basis of each logistics activity and the main operating conditions of each link. Improve technical equipment conditions. With the wide application of information technology, most logistics clusters enterprises have established management information systems, and the construction of logistics information platforms has been rapidly advanced.

Construct a reasonable logistics clusters network system and realize information sharing. The various enterprises in the clusters cooperate with each other to develop their core parts and develop together. Realize logistics interconnection and sharing. Plan and coordinate the integration and sharing of various information system resources, rationally allocate technical equipment, promote the sharing of information between logistics clusters, and promote the upgrading and upgrading of modern logistics services.

\section{Building a logistics clusters technology platform}

Building a logistics clusters technology platform has become one of the important forms of Ningbo's regional economic development. With the development of the Internet, the integration and networking within the logistics clusters is an inevitable development trend. The cooperation between industry and enterprises is also very important. With the development of society, it is necessary to integrate the network in order to make the market international and professional. In addition, it is necessary for each enterprise within the clusters to cooperate with each other and to do their own core parts in order to develop together. The combination of logistics and the 
Internet has created a huge development prospect for this industry, and to a certain extent, it has reduced the cost of enterprises and obtained more resources. It is necessary to establish a distinctive brand of Ningbo logistics clusters, form the centripetal advantage of clusters enterprises, build a relevant clusters platform, and promote local leading enterprises to carry out the development of small and mediumsized enterprises within the animal flow clusters, promote healthy competition within the clusters, and improve the level of logistics specialization.

\section{Promote the coordinated development of logistics clusters and port economic circles}

The first is the linkage between logistics clusters and the emerging formats of port and shipping logistics. Accelerate the guidance of ship and crew demand, realize the combination of crew service and ship service, combine the supply of production materials with the supply of living goods, combine sea service with land service, and fully form a "full support, strong function and wide radiation". International standards, domestic first-class ship and crew service system, to build an international maritime service base. The second is the linkage between logistics clusters and port industries. In combination with a group of 100 billion industrial development clusters in Ningbo, we will promote a new mode of new manufacturing industry.

\section{E. Strengthen the construction of logistics talents}

Optimize the talent training mechanism and accelerate the cultivation of a group of highly skilled personnel with technical skills, compound skills and knowledge and skills. In the context of international five-way operation, domestic market, and foreign market, we will deeply consider the development of the logistics industry value chain. In addition, the backbone personnel within the enterprise should actively go to the grassroots level of the enterprise for technical guidance and theoretical guidance. Grasp the introduction and cultivation of high-end logistics talents. Strengthen the cultivation of talents, build a network platform for multimodal transport, and enhance the use of infrastructure and professional transport.

\section{CONCLUSION}

According to the development characteristics of logistics clusters, this paper analyzes the logistics clusters in Ningbo, and puts forward suggestions on the status quo of industrial clusters from the aspects of system environment, factors and talents. And promotes the port economic circle that radiates the Yangtze River Delta and affects the East China film. The function of Ningbo's modern international port city has important significance.

\section{REFERENCES}

[1] John. Logistics clusters: delivering value and driving growth [M]. Y. Sheffi. MIT Press. 2012.

[2] Chen Yongping. Promotion of the Value Creating Capacity of Agricultural Products Logistics Industry from the Perspective of Resource Development [J]. Contemporary Finance \& Economics,2015(S1):99-112.

[3] Lv Yang, LI Xiao-xue. The Embryonic Stage Identification of Coldchain Logistics clusters in Eastern China[J]. Logistics technology, 2017, 40(05):58-65.

[4] Niu Guiqian.Discussion on Integrated Logistics Development in Ningbo City Ring [J]. Logistics Technology,2017,36(06):41-43+62.

[5] Li Guoqi, Jin Fengjun. Spatial patterns of logistics industry based on a geographic analysis of hotness degree [J]. Science Citation IndexExpand,2015,34(05):629-637.

[6] Wang Shuang. Cooperation-Competition Analysis for Regional Logistics clusters Development based on the BTH Integration[J] China Business and Market,2015,(01):112-117. 